\title{
An Okadaic Acid Fragment Analogue Prevents Nicotine-Induced Resistance to Cisplatin by Recovering PP2A Activity in Non-Small Cell Lung Cancer Cells
}

Raquel L. Arribas ${ }^{a}$, Anna Bordas ${ }^{a}$, Judit Domènech Omella ${ }^{b}$, Jose Luis Cedilloa, Veerle Janssens ${ }^{b}$, Carmen Montiele, ${ }^{a, *}$, Cristóbal de los Ríos ${ }^{a, c, *}$

a Department of Pharmacology and Therapeutic, Universidad Autónoma de Madrid. C/ Arzobispo Morcillo, 4, 28029 Madrid, Spain

${ }^{b}$ Department of Cellular \& Molecular Medicine. Laboratory of Protein Phosphorylation and Proteomics, KU Leuven. Herestraat 49, B-3000 Leuven, \& LKI (Leuven Cancer Institute), Belgium

c Instituto de Investigación Sanitaria, Hospital Universitario de la Princesa. C/ Diego de León, 62, 28006 Madrid, Spain

${ }^{*}$ Corresponding authors

E-mail addresses: carmen.montiel@uam.es, cristobal.delosrios@inv.uam.es

Abbreviations: NSCLC, non-small cells lung cancer; OA, okadaic acid; PP2A, phosphoprotein phosphatase $2 \mathrm{~A}$ 


\section{Abstract}

We herein report the design, synthesis, and functional impact of an okadaic acid (OA) small analogue, ITH12680, which restores the activity of phosphoprotein phosphatase 2A (PP2A), whose deficient activity has been implicated in nicotine-mediated tumor progression and chemoresistance in non-small cell lung cancer (NSCLC). For its design, we paid attention to the structure of the PP2A-OA complex, where the C16C38 OA fragment confers PP2A affinity and selectivity, but it is not involved in the inhibitory effect. Confirming this hypothesis, PP2A activity was not inhibited by ITH12680. By contrast, the compound partially restored OA-exerted PP2A inhibition in vitro. Moreover, flow cytometry and immunoblotting experiments revealed that ITH12680 reversed nicotine-induced cisplatin resistance in NSCLC cells, as it prevented nicotine-induced reduction of Bax expression and inhibited nicotinemediated activation of cell survival and proliferation kinases, Akt and ERK1/2. Our findings suggest that the rescue of nicotine-inhibited PP2A activity could diminish the resistance to cisplatin treatment observed in NSCLC patients who continue smoking.

Keywords: Computer-aided drug design; non-small cell lung cancer; phosphoprotein phosphatase $2 \mathrm{~A}$; chemoresistance; cisplatin; okadaic acid 


\section{Introduction}

Lung cancer, the most lethal type of malignant tumours, is characterized by the high number of cases diagnosed around the world and the poor survival rate within the first 5 years [1]. Tobacco consumption correlates with the $90 \%$ of lung cancer cases and the huge addiction that provokes makes cancer patients find difficult to quit smoking. As a consequence, lung cancer prevails as one of the main causes of death in the world, despite all the smoking prevention policies [2]. Non-small cell lung cancer (NSCLC) is the major sub-type of lung cancer, accounting for $75-85 \%$ of all the cases [3], and it is associated with a grim prognosis. The rise of a plethora of oncogenes and tumor proliferation mechanisms seems to be responsible of both initiation and proliferation of NSCLC $[4,5]$.

Therapeutic strategies to prolong NSCLC patients' life span, for instance by administrating tyrosine kinase inhibitors (TKI) or other cancer-targeted therapies, have only shown benefit in a limited group of patients [6]. Thus, 40 years after their approval by the FDA, the chemotherapeutic drug cisplatin and its derivatives remain the firstline treatment for a large group of NSCLC patients [7], despite the serious adverse effects detected upon their administration and the prevalence of the so dreaded chemoresistance [8]. Indeed, smoking not only correlates with the onset and progression of NSCLC, but it also decreases the effectiveness of any chemotherapy or radiotherapy. In particular, nicotine, the principal addictive component in tobacco, plays a key role in tobacco-mediated chemoresistance by inhibiting apoptosis and activating cell survival routes such as the Akt and ERK pathways that counteract the cytotoxic effects of chemotherapeutic agents, such as cisplatin [9]. Nicotine leads to cell survival and resistance to cisplatin by activating Akt kinase, that phosphorylates 
the pro-apoptotic protein Bax, reducing its stability [10]. By contrast, the protein phosphatase 2A (PP2A) dephosphorylates Bax, which favors apoptosis in tumor cells [11]. PP2A is a multimeric Ser/Thr phosphatase (S/T-PPP) composed of scaffold (A), catalytic (C) and regulatory (B) subunits, with the latter being responsible for subcellular localization, substrate specificity and function [12]. Recent evidence suggests that inactivation or inhibition of PP2A are key factors in NSCLC progression and chemoresistance [12], as it would induce overactivation of both survival and proliferation pathways, directly regulated by protein phosphorylation processes. In fact, PP2A is a well-known master suppressor of carcinogenesis and chemoresistance, as reported in many cancer types, such as leukemia [13], colorectal [14], gastric [15], hepatocellular carcinoma [16], breast [17], prostate [18], and renal [19] cancers, among others [20]. It has been described that endogenous PP2A inhibitors, e.g. SET (I2PP2A) or the cancerous inhibitor of PP2A (CIP2A), are over-expressed in many types of cancer, including NSCLC. For instance, it has been documented that the more SET expressed, the worse prognosis in NSCLC [21], while CIP2A is associated to Akt/mTOR axis up-regulation in several NSCLC cell lines [22].

For this reason, targeting endogenous PP2A inhibitors, in particular SET [23] or CIP2A [24], via the use of PP2A-activating drugs (PADs) [25] in combination with organoplatinum compounds or TKI compounds, is proposed as an interesting novel therapeutic strategy to restore the cytotoxic effects of antitumoral drugs [26]. In particular, we propose the design of PP2A ligands capable of hindering the action of PP2A inhibitors without compromising the PP2A enzymatic activity. There is only one example in the literature of a class of direct PADs studied for antitumoral therapy: the phenothiazine perphenazine [27], and its improved derivatives, called SMAPs (Small Molecule Activators of PP2A) [28, 29]. These compounds bind to the structural PP2A 
A subunit and are suspected to act by poorly understood allosteric effects [27, 28]. However, since CIP2A, SET, and other PP2A regulators are thought to directly or indirectly interact with the catalytic PP2A C subunit (PP2Ac) [30-32], we hypothesize that the best way to prevent the formation of PP2A-inhibitor complexes would be through the development of directed ligands of the PP2Ac subunit.

In our research group, we are interested in the design, synthesis, and biological evaluation of PP2A activators $[33,34]$ to hamper the action of PP2A inhibitors. A widely-used experimental model of PP2A impairment is that resembled by the selective PP2A inhibitor okadaic acid (OA; Fig. 1) [35], which has afforded important scientific breakthroughs [36]. This marine toxin, initially isolated from Halichondria okadai, is present in other microorganisms like dinoflagellates [37]. Structure-activity relationships studies of OA related to its inhibitory potential over PP2A, have shown very interesting findings (Fig. 1) [38]. The C1-C5 fragment of OA, by mimicking a PP2A-targeted $p$ Thr, carries out the enzymatic inhibition [39]. Besides, hydrophobic heterocyclic cores, located between $\mathrm{C} 16$ and $\mathrm{C} 38$ of OA (Fig. 1), allow greater selectivity for PP2A than for other S/T-PPP, and they indeed lack PP2A inhibitory activities by themselves $[40,41]$. Based on these insights, we propose that small OA fragments that lacked the PP2A-inhibiting $\mathrm{C} 1-\mathrm{C} 15$ end could maintain affinity and selectivity for PP2A without inhibiting its phosphatase activity. Moreover, these small OA derivatives, analogues to the $\mathrm{C} 16-\mathrm{C} 38$ fragment, could prevent the binding of endogenous inhibitors to the PP2A catalytic subunit, thereby preventing the formation of PP2A-inhibitor complexes. In the end, PP2A activity would be protected or even recovered. Fig. 1 reveals that a small compound that we have named ITH12680, which is a key intermediate in the Isobe's total synthesis of OA [42], shows structural similarities with a small portion of the OA C16-C38 fragment. Consequently, we aimed 
to demonstrate that this small OA fragment analogue could restore PP2A inhibition and, as a consequence, this pharmacological effect could have therapeutic relevance to abrogate tobacco-induced chemoresistance in NSCLC.
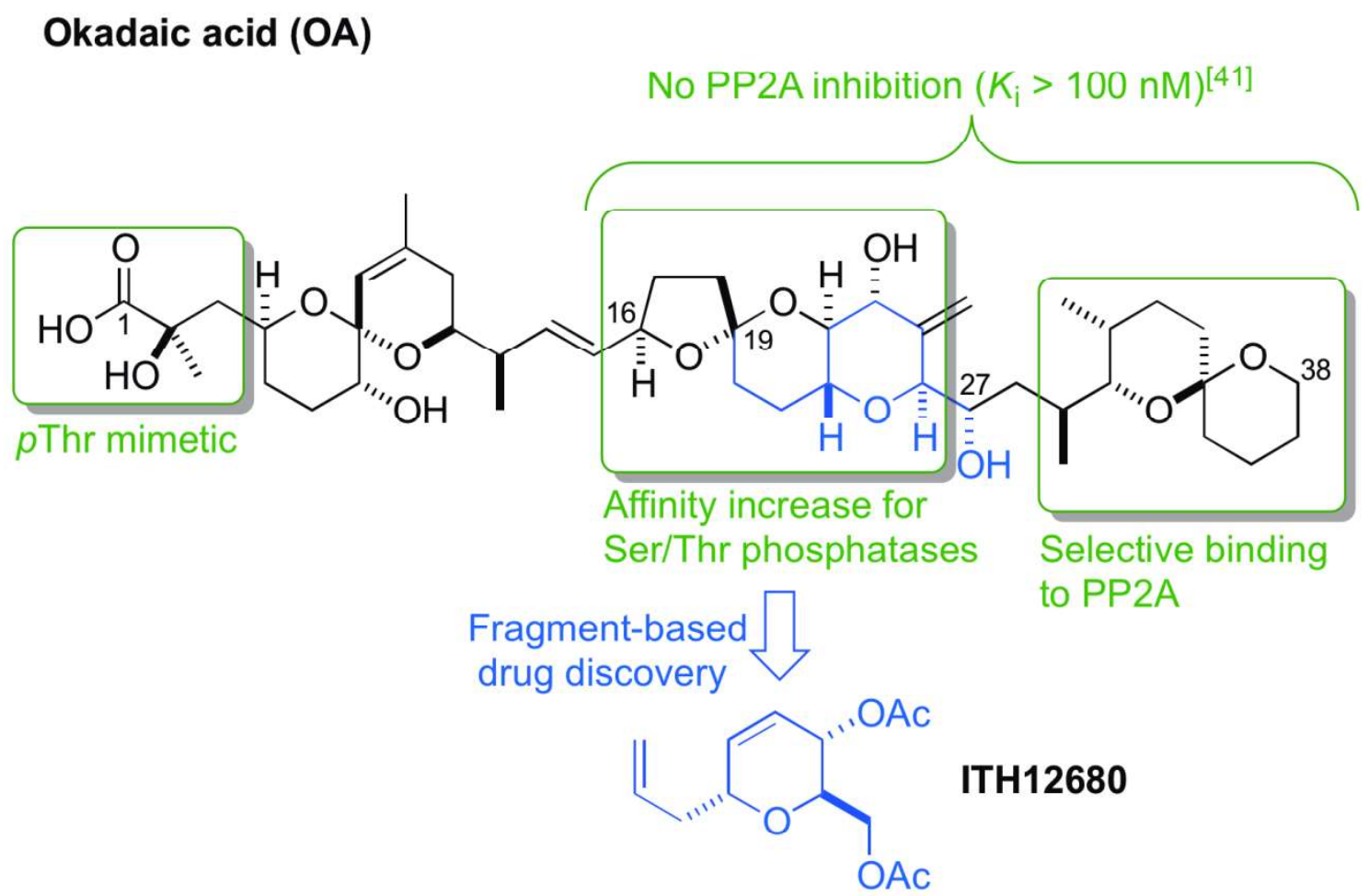

Fig. 1. Chemical structure of okadaic acid (OA), with a scheme of the SAR studies reported in literature; and ITH12680, which shows structural similarities with the OA C16-C38 fragment.

\section{Results and Discussion}

ITH12680 was synthesized through the Hosomi-Sakurai electrophilic addition of allyltrimethylsilane with D-glucal triacetate, assisted by $\mathrm{BF}_{3} \cdot \mathrm{Et}_{2} \mathrm{O}$ (Scheme 1), according to the literature [42], furnishing the compound with quantitative yield and high diastereoselective excess ( $>96 \%$, by NMR). 

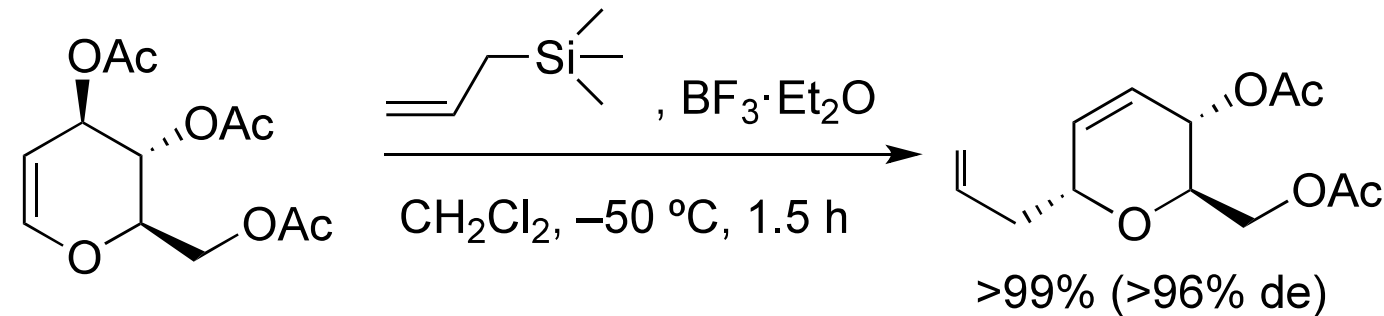

ITH12680

Scheme 1. Synthesis of ITH12680 by the Hosomi-Sakurai procedure

We ran a computational docking of ITH12680 on a large area of the PP2A catalytic binding site, using the AC dimer structure deposited in the Protein Data Bank (2IE4; http://www.rcsb.org)(Fig. 2). Fig. 2A shows that ITH12680 (yellow sticks) docks into the hydrophobic pocket of PP2Ac that would also surround the C29-C38 fragment of OA (green sticks). At this position, ITH12680 binds amino acids implicated in recognizing the OA C29-C38 end fragment, being those ones the responsible for the inhibitory selectivity to PP2A (Fig. 2). Xing et al. reported that the OA C1-C5 fragment interacts with Leu243, Tyr265, Cys266, Arg268, and Cys269 of PP2Ac, which are the amino acids in charge of carrying out the phosphate ester hydrolysis of phosphoprotein substrates [38]. In contrast, the amino acids GIn122, lle123, His191, and Trp200 of PP2A build a hydrophobic pocket that accommodates either the OA C29-C38 fragment [38] or the compound ITH12680 (Fig. 2B). ITH12680 elicits three main chemical interactions within this hydrophobic pocket (Fig. 2B): the carbonyl of the acetyloxy group at $\mathrm{C} 3$ forms a $\mathrm{H}$-bond of $1.74 \AA$ with the $\mathrm{OH}$ at $\mathrm{Ser} 120$, and the oxygen bound to $\mathrm{C} 3$ forms a $\mathrm{H}$-bond of $2.52 \AA$ with the indole $\mathrm{NH}$ at Trp200. The pyran oxygen of ITH12680 generates a H-bond of $2.84 \AA$ with the imidazole NH of His191. Finally, the pending propenyl group of ITH12680 faces Ala216 in a hydrophobic fashion. 
A

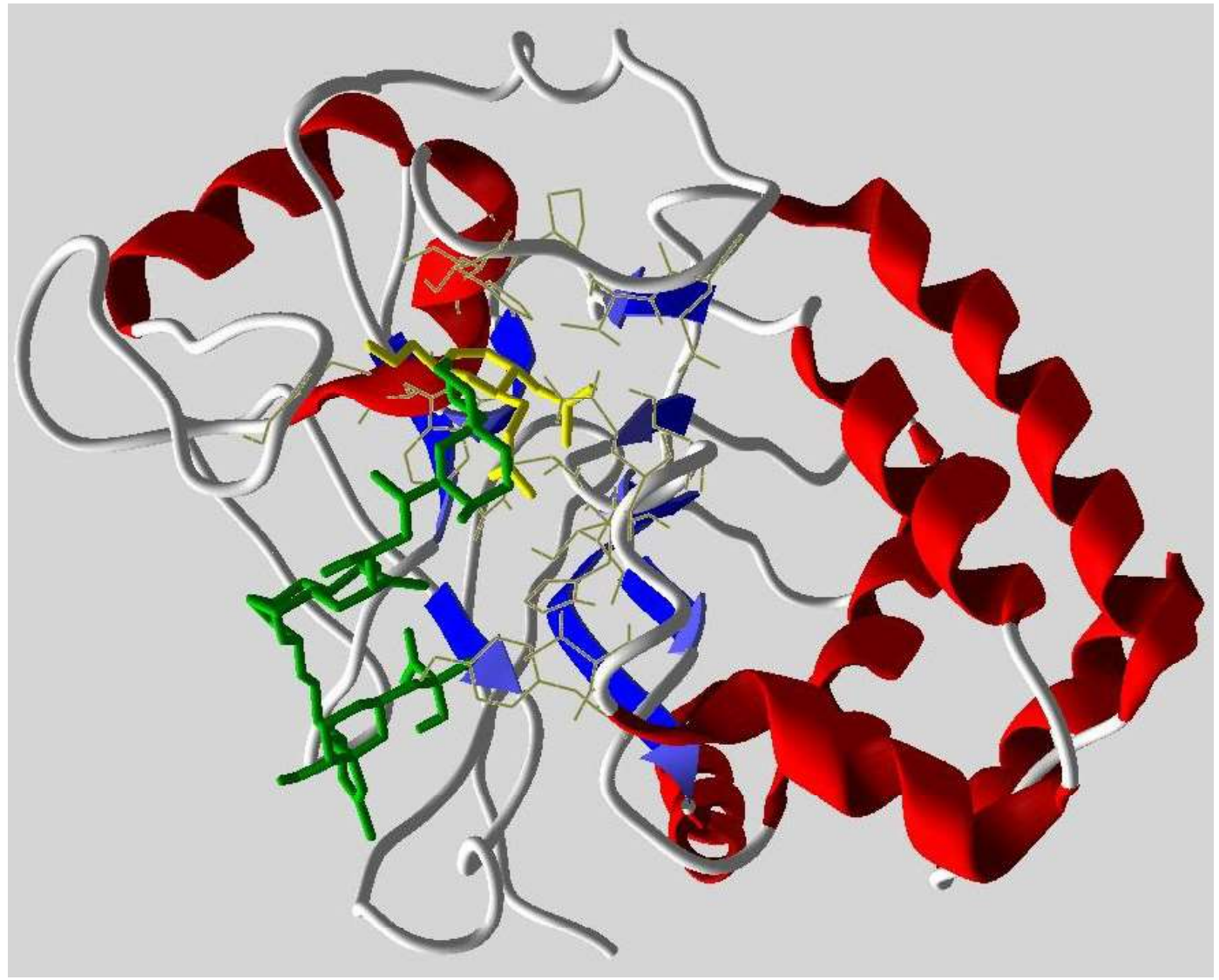




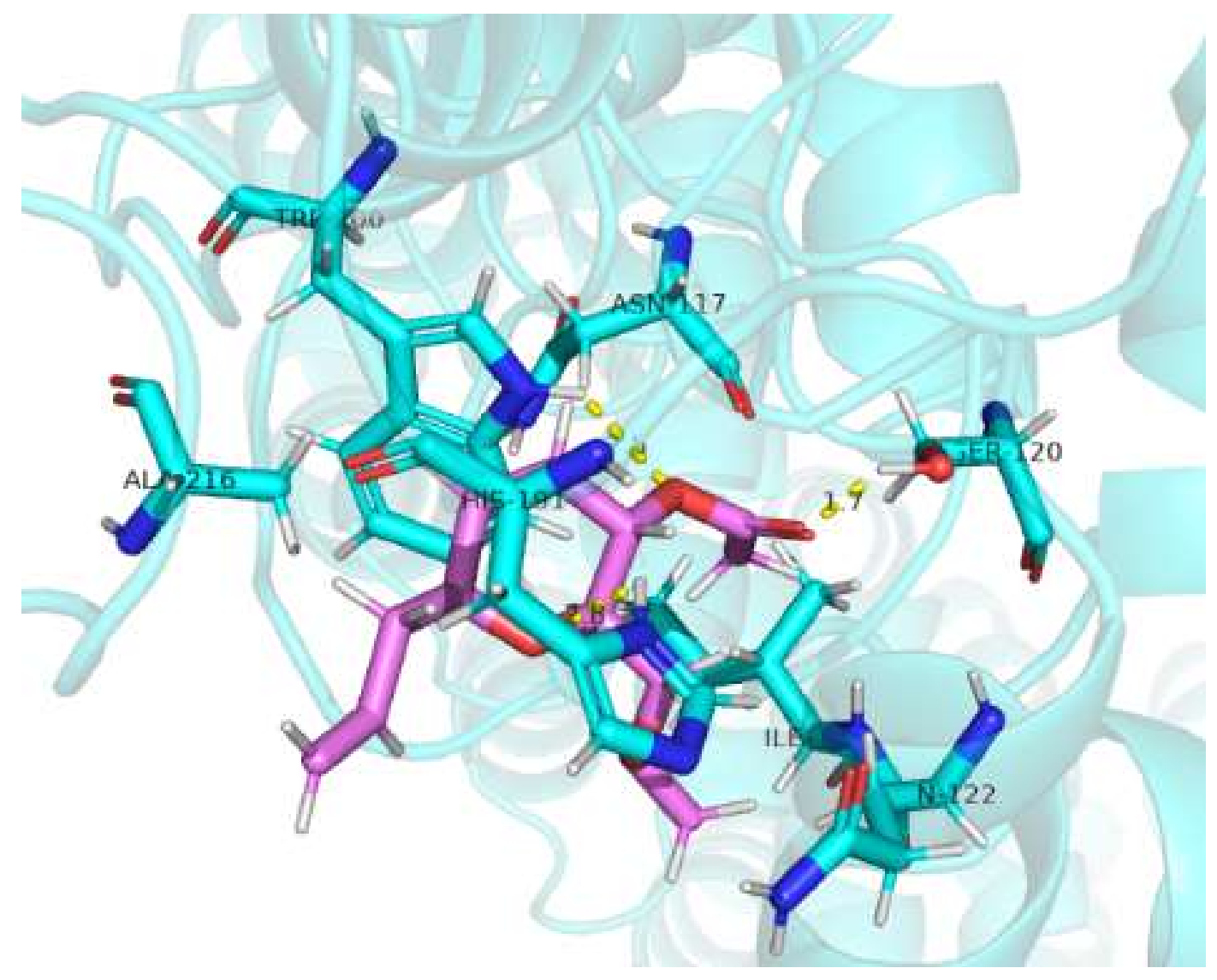

Fig. 2. Molecular docking of ITH12680-PP2A complex. (A) Positioning of ITH12680 (yellow) and OA (green) within PP2A-C subunit. (B) Main interactions of ITH2680 (pink stick) with amino acids (blue sticks) of the binding pocket generated by Trp200, Asn117, Gln122, and His191.

Overall, our computational study predicts that ITH12680 would show affinity for a peripheral PP2A-binding pocket not found in other S/T-PPP, which is located far from the PP2A catalytic site. Therefore, ITH12680 would not inactivate PP2A, but it could disrupt OA inhibitory potential. To support this hypothesis, the phosphatase activity was measured in different PP2A preparations with the malachite green assay, using the phospho-peptide K-R-pT-I-R-R as a substrate, in the presence or the absence of OA, either with or without ITH12680 (Fig. 3). First, an N-terminally GFP-tagged PP2A- 
$\mathrm{C} \alpha$ (PPP2CA gene) subunit was ectopically expressed in HEK293T cells and isolated from the total cell lysate by GFP-trapping. GFP, used as a bait protein, facilitated the isolation of the PP2A with the $\mathrm{C} \alpha$ subunit by the "pull-down" method (experimental details in supplementary material). Phosphatase activity of purified PP2A-C $\alpha$ was inhibited by $31 \%$ in the presence of $15 \mathrm{nM}$ OA (Fig. 3A). Such OA-compromised PP2A$\mathrm{C} \alpha$ phosphatase activity was partially recovered by ITH12680 at $50 \mu \mathrm{M}$ in a concentration-dependent manner (Fig. 3A). For this reason, we selected $50 \mu \mathrm{M}$ to test the ability of ITH12680 to recover the phosphatase activity of the principal PP2A isoforms that regulate cell survival and proliferation. Indeed, PP2A isoforms possessing $\mathrm{B} \alpha$ or $\mathrm{B}^{\prime} \alpha$ subunits are major mediators in the dephosphorylation of phosphoprotein substrates, such as Akt and ERK1/2 [43]. PP2A-B $\alpha$ and PP2A-B' $\alpha$ enzymes showed slightly different sensitivities to $O A$, since respective concentrations of 15 or $20 \mathrm{nM}$ of the inhibitor were required to achieve the same inhibition (about 30\%) in each isoform (Fig. 3B and 3C). Noteworthy, ITH12680 had a similar effect in B $\alpha$ (PPP2R2A) or B' $\alpha$ (PPP2R5A)-transfected HEK293T cells (Fig. 3B and 3C). 
A

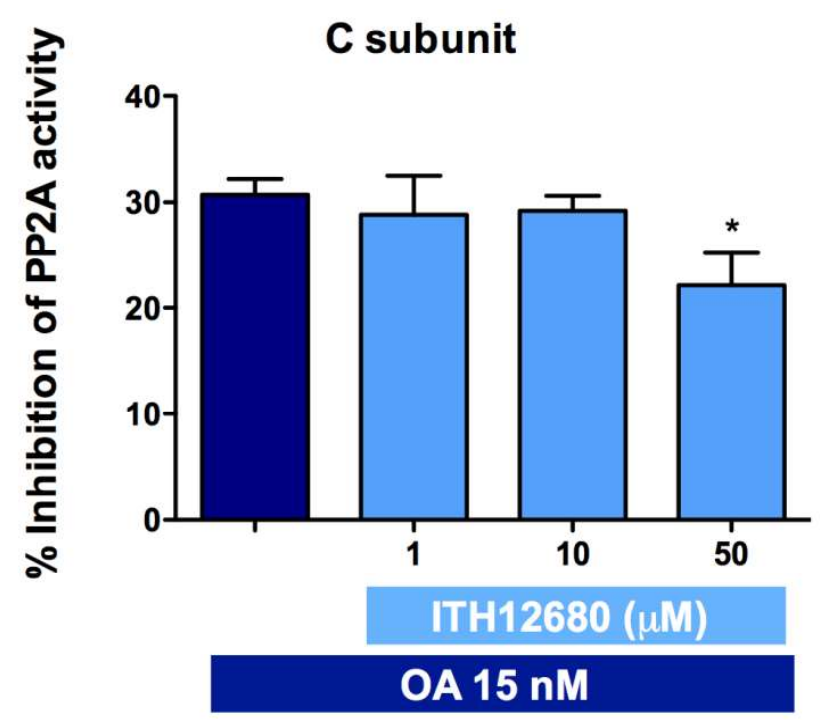

B

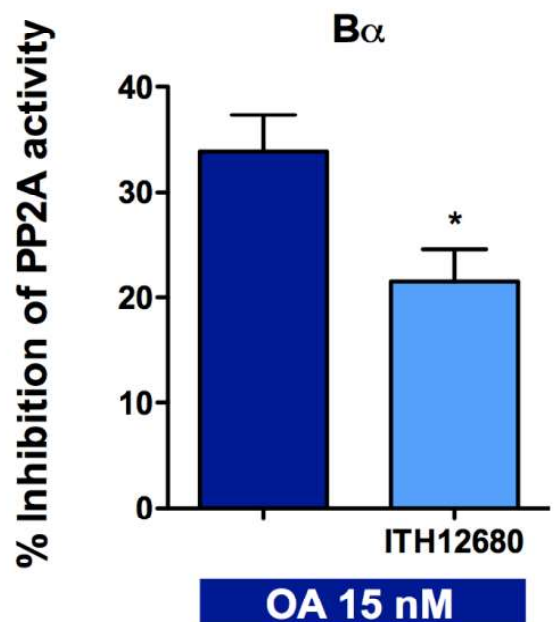

C

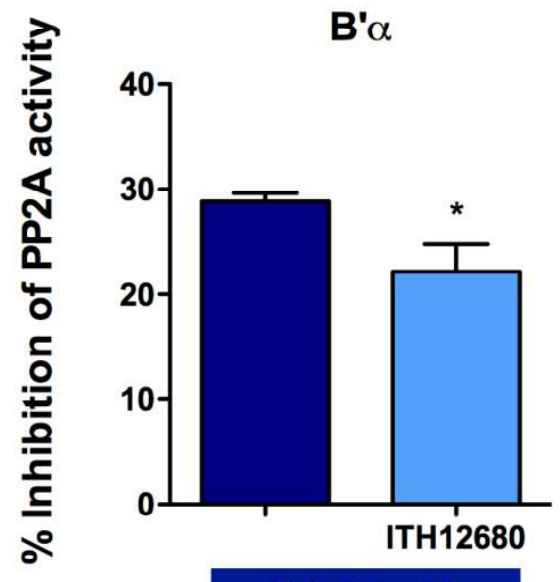

\section{OA $20 \mathrm{nM}$}

Fig. 3. PP2A activity measured by malachite green assay on K-R-pT-I-R- R phosphopeptide. PP2A was isolated from GFP-C $\alpha$ (A), GFP-B55 $\alpha(B \alpha ; B)$ or GFP-B56 $\alpha$ (B' $\alpha$, C) transfected HEK293T cells by the "pull-down" method, using GFP as the bait protein. PP2A was allowed to hydrolyze the phosphor-peptide substrate for $30 \mathrm{~min}$. Similar results were found when reaction time was 15 min (data not shown). Data represented as normalized percentage of inhibition of PP2A compared to PP2A 
precipitates treated with vehicle $(100 \%$ activity). Data were means \pm SEM from four independent experiments. ${ }^{*} P<0.05$ compared with cells treated with $\mathrm{OA}$.

Once confirmed that ITH12680 was able to recover the PP2A-catalyzed phosphatase activity compromised by a PP2A inhibitor, we next tested whether this PP2A upregulating behavior could be beneficial in the antitumoral chemotherapy of the NSCLC. We assessed the effect of ITH12680 on the cell viability of human lung adenocarcinoma A549 cells (Fig. 4), compared with that of fingolimod (FTY720), the best-known PAD [44]. We found that ITH12680 did not induce cytotoxicity in A549 cells (Fig. 4A), unlike FTY720, which elicited a dramatic, concentration-dependent drop in cell viability (Fig. 4B). 
A

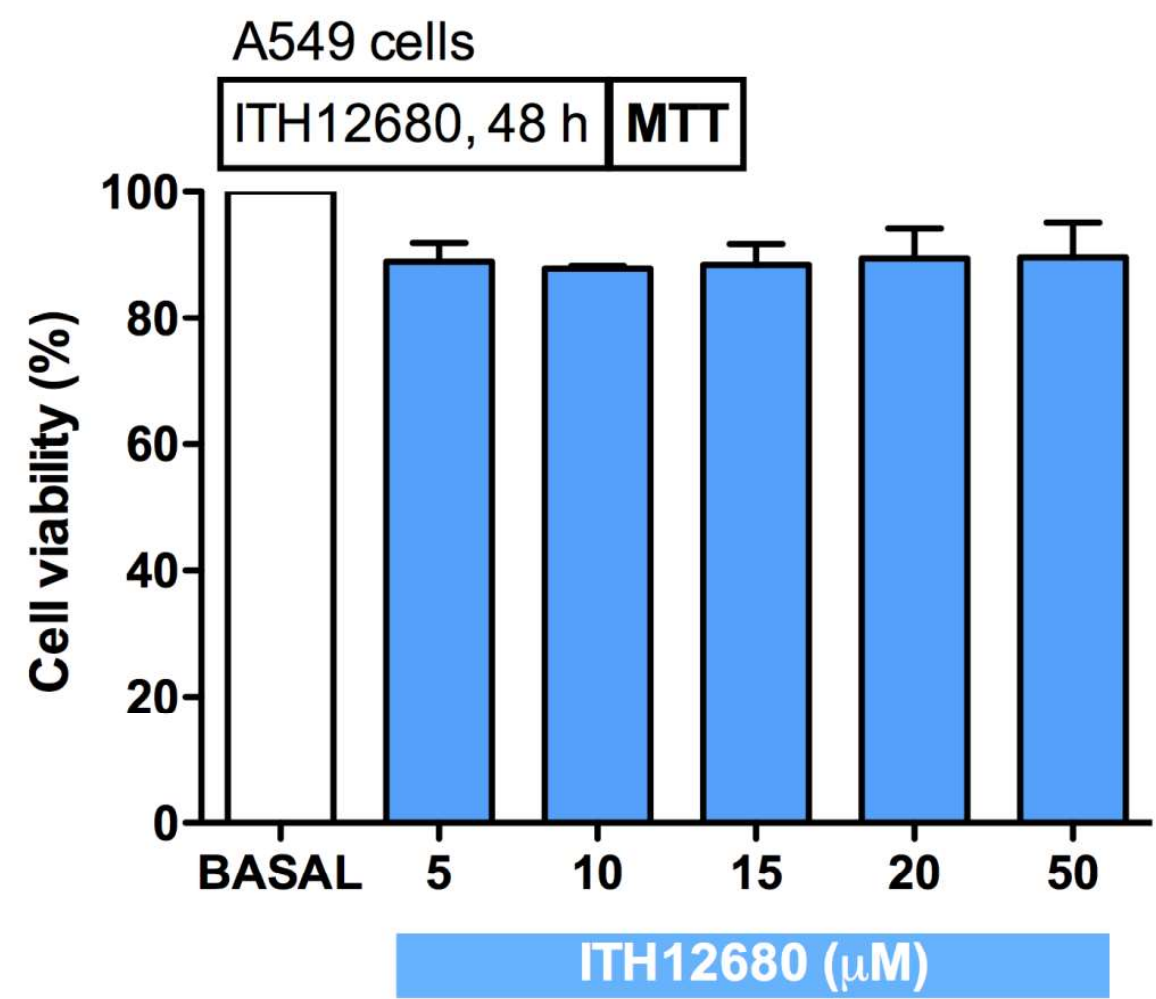

B

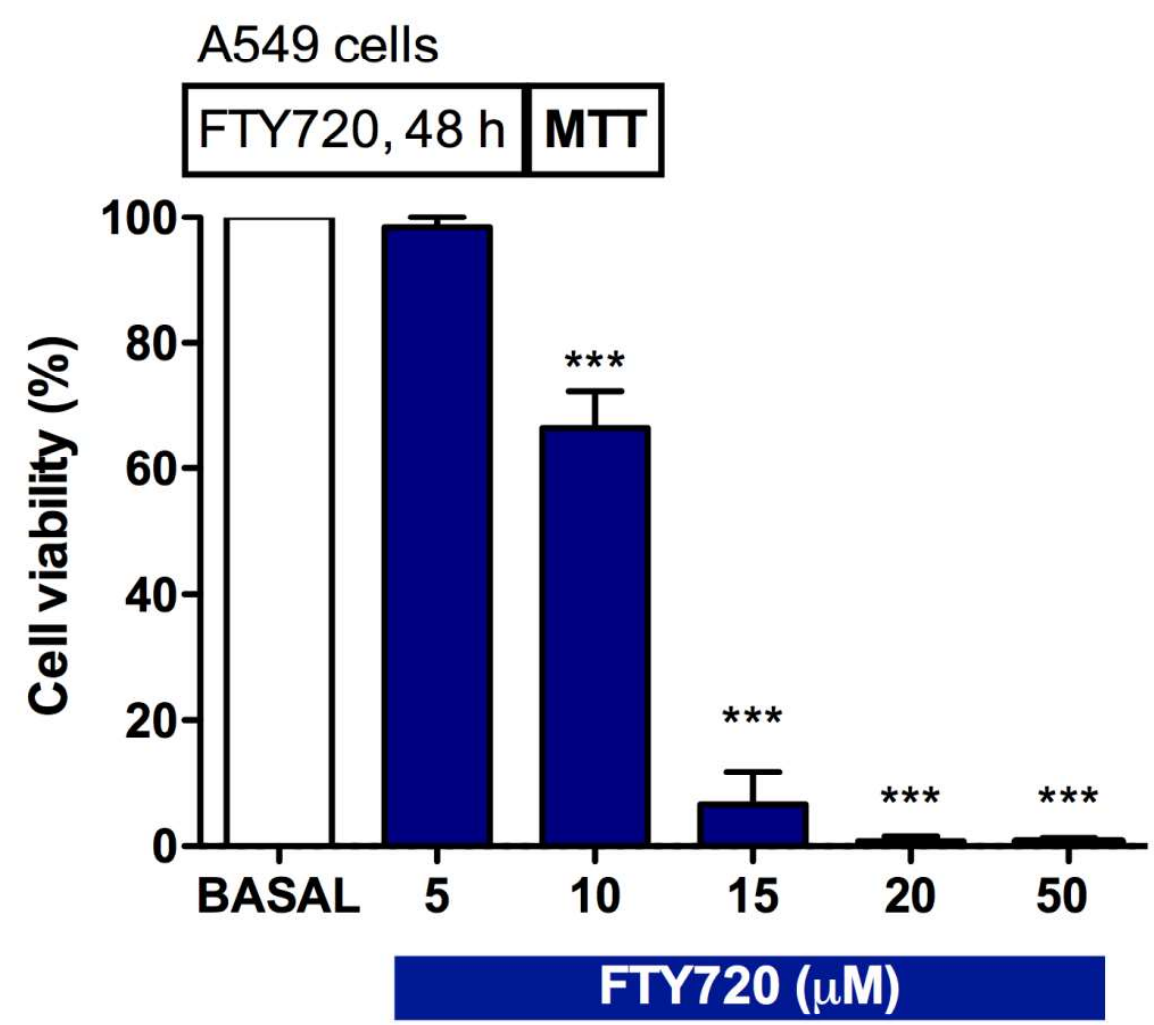

Fig. 4. Cytotoxicity of ITH12680 (A) and FTY720 (B) in A549 cells was evaluated by the MTT assay. After incubation of compounds, MTT was added to cells and its 
chemical reduction was allowed for $3 \mathrm{~h}$. Data are expressed as percentage of viability in non-treated cells (BASAL), and presented as the mean \pm SEM from three independent experiments. ${ }^{* * *} P<0.001$ compared to BASAL.

FTY720 is described to produce, in addition to its recognized sphingosine-1P (S1P) receptor agonist profile, an upregulation of PP2A activity, presumably by inhibiting $\mathrm{I}_{2} / \mathrm{SET}$ [23], albeit at much higher concentrations than those where we observed cytotoxicity (Fig. 4B) [45]. Moreover, its immunosuppressive effect [46] would entail unadvisable its chemotherapeutic use. In contrast, ITH12680, which presented PAD profile at $50 \mu \mathrm{M}$ (Fig. 3), did not reduce A549 cell viability by itself (Fig. 4A).

In light of this, we hypothesize that ITH12680, by up-regulating PP2A activity, could favor the dephosphorylation of phosphoprotein kinases implicated in cell survival and proliferation, and thus mitigating the resistance to cisplatin in NSCLC cells. To examine this hypothesis, we designed experiments to evaluate whether $50 \mu \mathrm{M}$ ITH12680 could affect nicotine-induced cisplatin resistance in A549 cells, a phenomenon previously shown to be mediated by nicotine-induced phosphorylation of survival kinases and inactivation of the proapoptotic protein Bax [9]. Flow cytometry data with propidium iodide (PI) and Annexin V-FITC staining revealed that ITH12680 completely restored the proapoptotic capacity of cisplatin previously altered by the presence of nicotine (Fig. 5).

This feature and the lack of intrinsic cytotoxicity at that concentration provide an enormous advantage to our compound over FTY720. 
A

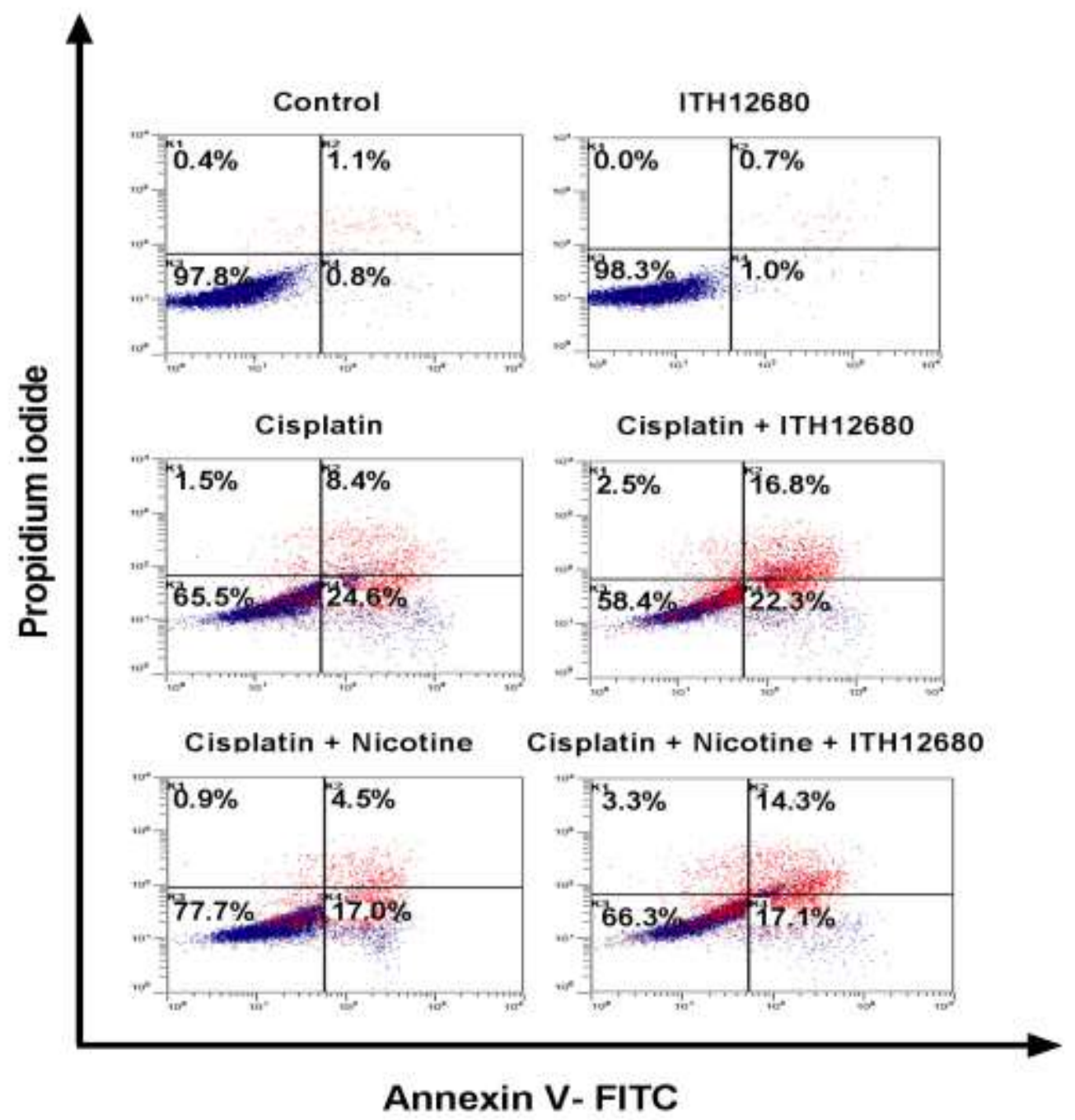

B

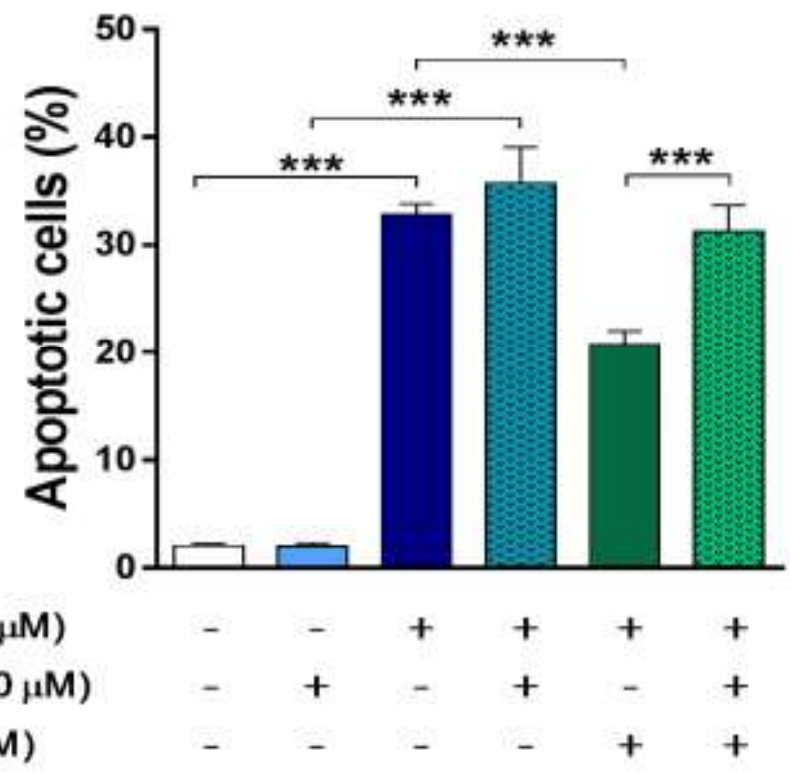


Fig. 5. Apoptosis in A549 cells measured by flow cytometry with propidium iodide (PI) and Annexin V-FITC staining. (A) Scatter plot, expressing in each condition: necrotic (Annexin-V-/PI+; upper-left quadrant), late apoptotic (Annexin-V+/PI+; upper-right quadrant), early apoptotic (Annexin-V+/PI-; lower-right quadrant) or living cells (Annexin-V-/PI-; lower-left quadrant), after indicated treatments. (B) Percentage of apoptotic cells (late plus early ones) in response to the treatments. Data are mean \pm SEM from five independent experiments. ${ }^{* * *} P<0.001$.

Complementary immunoblotting experiments in A549 cells further underscored the mechanism behind the ITH12680-mediated prevention of the nicotine-induced chemoresistance. Similar to what is widely reported in literature [9], nicotine increased expression of both phospho-Akt (p-Akt) and phospho-ERK1/2 (p-ERK1/2) in cisplatintreated A549 cells (Fig. 6A and 6B). As a result of activation of both kinases, the survival signaling pathways that lead to cisplatin resistance are enhanced [47]. Fig. 6 shows that the presence of ITH12680 at $50 \mu \mathrm{M}$ prevented the nicotine-evoked p-Akt and p-ERK1/2 increase (Fig. 6A and 6B). On the other hand, cisplatin induced the expression of the proapoptotic Bax protein in A549 cells (Fig. 6C), an effect that was significantly reversed by nicotine, a finding consistent with earlier publications [9-11]. Noteworthy, ITH12680 increased Bax expression in cisplatin-treated A549 cells, thus abolishing the action of nicotine (Fig. 6C). Overall, ITH12680 fully antagonizes the effects of nicotine, so this compound is able to produce a full recovery of the cisplatinmediated responses. Furthermore, p-Akt and p-ERK1/2 are responsible of inducing survival pathways upon long period of cisplatin administration, thus also leading to chemoresistance [47]. Hence, these experiments would support the use of ITH12680 
to prevent such chemoresistance, and validate PP2A as a master regulator of apoptosis/survival mechanisms in NSCLC.

A
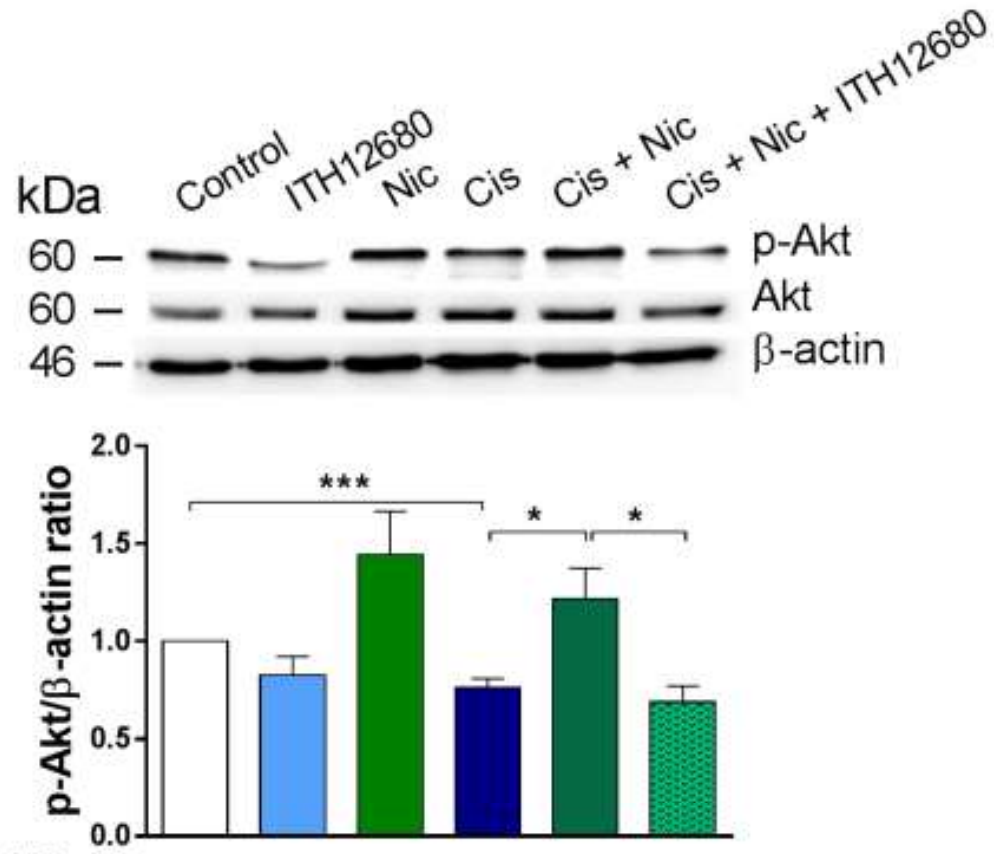

Cisplatin $(10 \mu \mathrm{M}) \quad-\quad-\quad-\quad+\quad+\quad+$

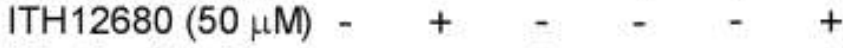

Nicotine $(1 \mu \mathrm{M}) \quad-\quad-\quad+-++$ 


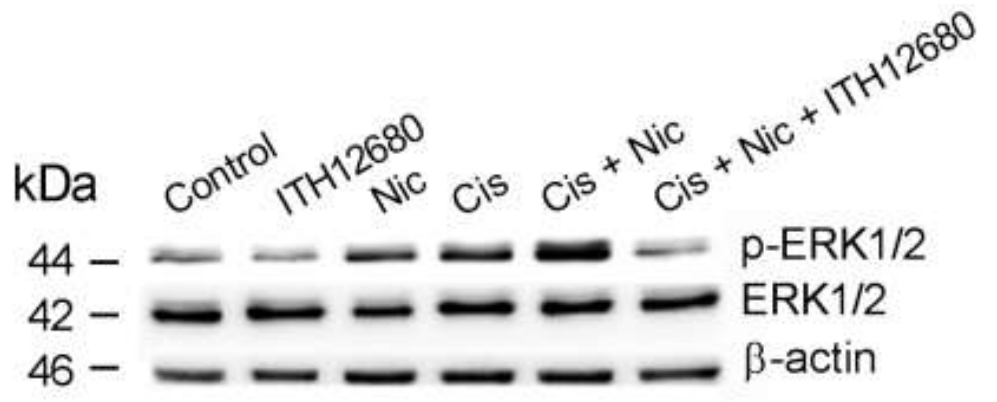

Cisplatin $(10 \mu \mathrm{M})$

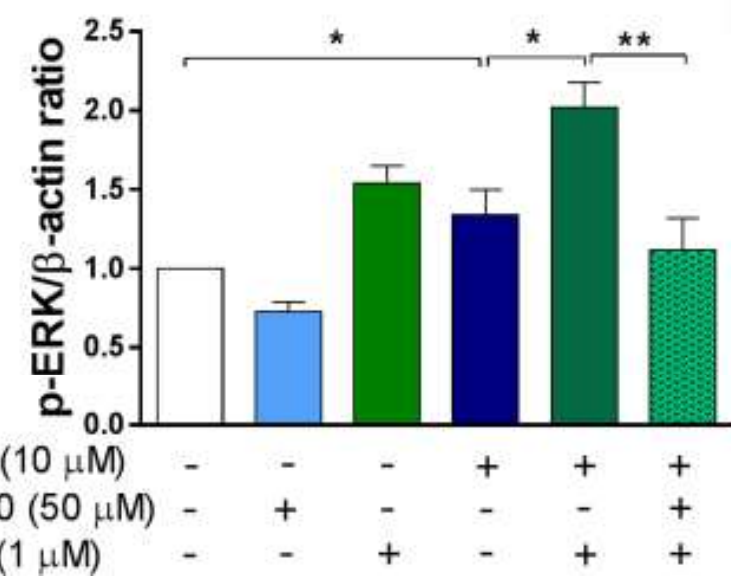

C

Nicotine $(1 \mu \mathrm{M})-\mathrm{C}^{-}+-++$

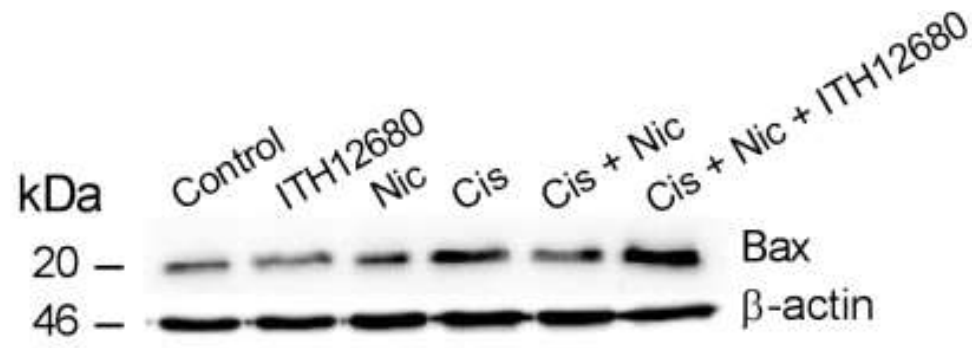

Cisplatin $(10 \mu \mathrm{M})$

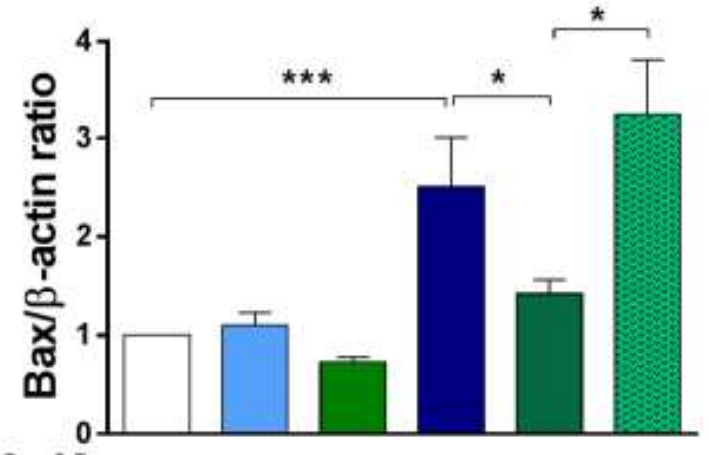

ITH12680 $(50 \mu \mathrm{M})-+-\quad-\quad+$ Nicotine $(1 \mu \mathrm{M})-\mathrm{C}^{-}+-++$ 
Fig. 6. Analysis of p-Akt (A), p-ERK1/2 (B), and Bax (C) expression in A549 cells exposed to different treatments. Cisplatin was applied to A549 cells for $48 \mathrm{~h}$, in the absence or presence of nicotine and/or ITH12680, administered $24 \mathrm{~h}$ before and during cisplatin exposure. (Top) Immunoblots of representative experiments. (Bottom) Mean \pm SEM from five independent experiments. ${ }^{*} P<0.05,{ }^{* *} p<0.01,{ }^{* * *} p<0.001$.

Moreover, a possibility exists that ITH12680 was up-regulating PP2A by inhibiting its endogenous inhibitors, e.g. SET or CIP2A, which are indeed overexpressed in several types of cancer, such as NSCLC, and originate a poorer prognosis [21, 22]. As a first glance, compound ITH12680 seemed not to inhibit CIP2A or SET expression, as evidenced by western-blot (Fig. 7).

A
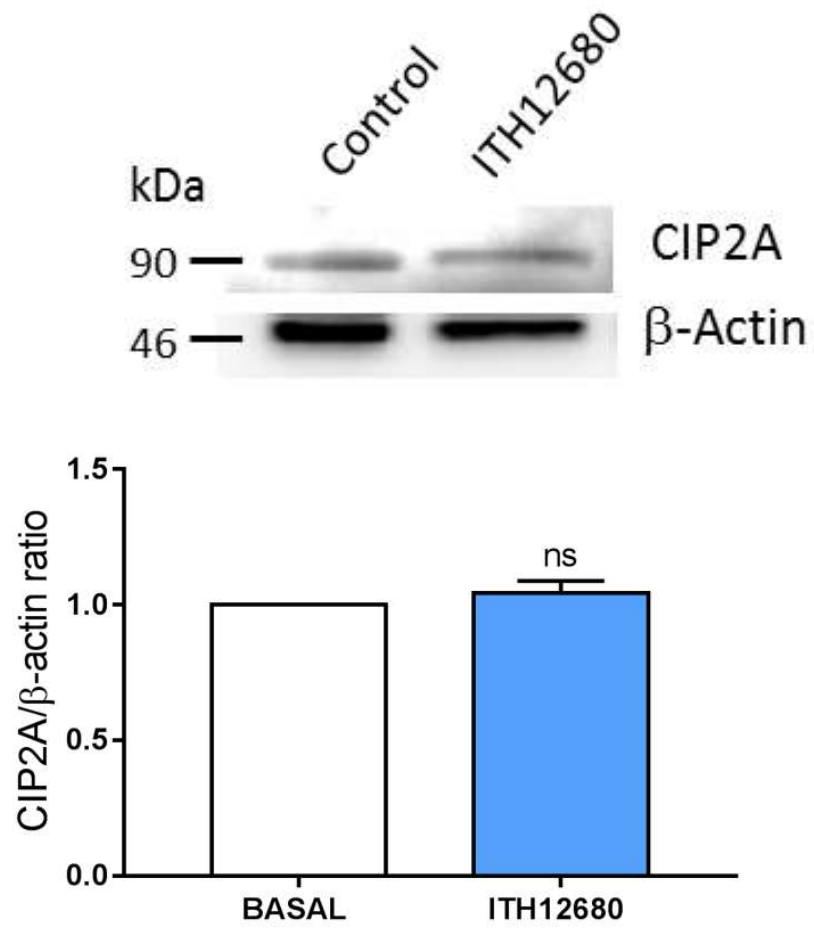
B
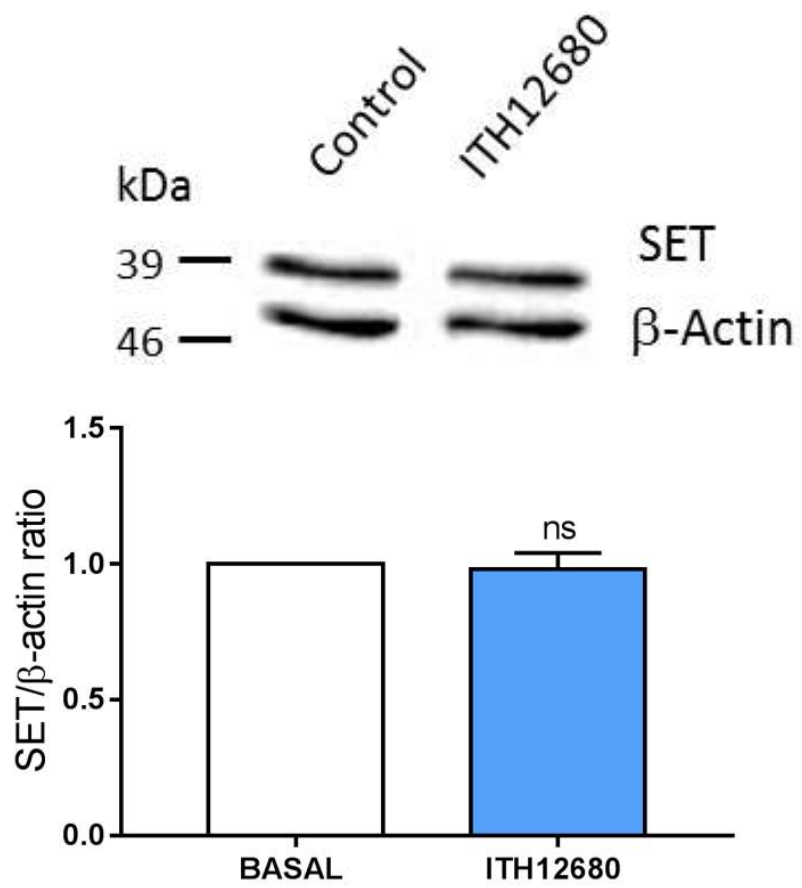

Fig. 7. Analysis of CIP2A (A) and SET (B) expression, in the presence or absence of ITH12680 at $50 \mu \mathrm{M}$, measured by western-blot. ITH12680 was applied to A549 cells for $24 \mathrm{~h}$. An immunoblot for a representative experiment is shown over the pooled data. Data are mean \pm SEM from five independent experiments. Ns $=$ not significant.

Therefore, our results support the hypothesis that ITH12680 prevents nicotine-induced resistance to cisplatin in NSCLC cells through the reactivation of the PP2A function, thus leading to $\mathrm{p}-\mathrm{Akt}$ and $\mathrm{p}$-ERK $1 / 2$ dephosphorylation, and increasing the expression of the proapoptotic Bax protein.

\section{Conclusions}

In summary, we present the rational design of a PP2A catalytic subunit (PP2Ac) ligand that partially restores the compromised PP2A activity in vitro and, as a consequence, fully prevents the antiapoptotic activity of nicotine in cisplatin-treated NSCLC cells, 
process reported to depend on changes in the phosphorylation of survival kinases and Bax. Nicotine and other tobacco components induce various cell survival pathways controlled by reversible protein phosphorylation, explaining the beneficial effect of a PP2A re-activating compound. Several PADs have been studied for cancer treatments in recent years $[23,48,49]$, but all of them produced indirect PP2A upregulation. FTY720, the most studied PAD, has also being tested as an adjuvant of cisplatin [26], although its immunosuppressant effects limit its use in cancer [46].

Although not clear from the literature, several PP2A inactivating mechanisms might contribute to the nicotine-induced inactivation of PP2A in A549 cells, including increased expression of cellular inhibitors such as SET or CIP2A, but also downregulation of specific PP2A subunits or increases in different inactivating posttranslational modifications of PP2A [50]. Given that ITH12680 logically acts by directly targeting the PP2Ac, we presume that the cellular effects of the compound are likely best explained by its prevention of the action of cellular PP2A inhibitors, which likely also directly or indirectly target PP2Ac [30-32]. However, due to the low binding affinities of PP2A to these cellular inhibitors, and our consistent failures to coprecipitate CIP2A or SET with PP2A from cells, it proved difficult to experimentally address this possibility. In any case, such a hypothesis would also explain why the ITH12680 compound shows much more pronounced PP2A reactivation effects in cells than in the in vitro competition assay with $O A$, since $O A$ indeed shows much higher affinity for PP2A than the cellular PP2A inhibitors, and thus higher ITH12680 concentrations will be required to achieve a similar level of competition. That ITH12680 clearly shows a lower affinity for PP2A than OA should on the other hand not come as a surprise, as the PP2A inhibiting part of OA (C1-C5, which is absent in ITH12680) may additionally contribute to OA's affinity for PP2A. 
Lung cancer is the most lethal type of cancer at present. Current treatments have failed in terms of efficacy and the appearance of chemoresistance. Considering that the PP2A loss-of-function represents a major event leading to cancer progression that can be even further pronounced by the action of nicotine, we propose the use of ITH12680 in combination with cisplatin as an attractive pharmacological strategy against malignancies, such as NSCLC, since it can help to overcome chemoresistance. Furthermore, the therapeutic use of this new PAD might be extended to other diseases in which PP2A inhibition by cellular inhibitors impacting on the PP2Ac active site, such as SET, CIP2A and PME-1, plays a pathogenic role.

\section{Acknowledgments}

This work has been supported by the following grants: SAF2017/82689-R (Ministerio de Economía y Competitividad, Spain, to C.M.) and PI16/01041 (IS Carlos III, Spain, to C.d.I.R; co-funded by FEDER), FAF-F/2016/822 (Belgian Foundation Against Cancer; to V.J.) and C24/17/0773 (KU Leuven; to V.J.). R.L.A and A.B. thank Universidad Autónoma de Madrid (UAM) for predoctoral fellowships. J.D.O. was funded by a F.W.O.-SB fellowship of the Research Foundation-Flanders.

\section{Appendix A. Supplementary material}

Supplementary data to this article can be found online at: https://doi.org/10.1016/j.bioorg.2020.xx.xxx.

\section{References}


[1] D.S. Ettinger, W. Akerley, H. Borghaei, A.C. Chang, R.T. Cheney, L.R. Chirieac, T.A. D'Amico, T.L. Demmy, R. Govindan, F.W. Grannis, Jr., S.C. Grant, L. Horn, T.M. Jahan, R. Komaki, F.M. Kong, M.G. Kris, L.M. Krug, R.P. Lackner, I.T. Lennes, B.W. Loo, Jr., R. Martins, G.A. Otterson, J.D. Patel, M.C. PinderSchenck, K.M. Pisters, K. Reckamp, G.J. Riely, E. Rohren, T.A. Shapiro, S.J. Swanson, K. Tauer, D.E. Wood, S.C. Yang, K. Gregory, M. Hughes, Non-small cell lung cancer, version 2.2013, J. Natl. Compr. Canc. Netw., 11 (2013) 645653; quiz 653.

[2] R. Siegel, D. Naishadham, A. Jemal, Cancer statistics, 2013, CA Cancer J. Clin., 63 (2013) 11-30.

[3] J. Ferlay, I. Soerjomataram, R. Dikshit, S. Eser, C. Mathers, M. Rebelo, D.M. Parkin, D. Forman, F. Bray, Cancer incidence and mortality worldwide: sources, methods and major patterns in GLOBOCAN 2012, Int. J. Cancer, 136 (2015) E359-386.

[4] C.R. Chong, P.A. Janne, The quest to overcome resistance to EGFR-targeted therapies in cancer, Nat. Med., 19 (2013) 1389-1400.

[5] K. Rihawi, R. Alfieri, M. Fiorentino, F. Fontana, E. Capizzi, A. Cavazzoni, M. Terracciano, S. La Monica, A. Ferrarini, G. Buson, P.G. Petronini, A. Ardizzoni, MYC Amplification as a Potential Mechanism of Primary Resistance to Crizotinib in ALK-Rearranged Non-Small Cell Lung Cancer: A Brief Report, Transl. Oncol., 12 (2018) 116-121.

[6] G.G. Sharma, I. Mota, L. Mologni, E. Patrucco, C. Gambacorti-Passerini, R. Chiarle, Tumor Resistance against ALK Targeted Therapy-Where It Comes From and Where It Goes, Cancers (Basel), 10 (2018). 
[7] C.E. Steuer, M. Behera, V. Ernani, K.A. Higgins, N.F. Saba, D.M. Shin, S. Pakkala, R.N. Pillai, T.K. Owonikoko, W.J. Curran, C.P. Belani, F.R. Khuri, S.S. Ramalingam, Comparison of Concurrent Use of Thoracic Radiation With Either Carboplatin-Paclitaxel or Cisplatin-Etoposide for Patients With Stage III NonSmall-Cell Lung Cancer: A Systematic Review, JAMA Oncol., 3 (2017) 11201129.

[8] Z.H. Siddik, Cisplatin: mode of cytotoxic action and molecular basis of resistance, Oncogene, 22 (2003) 7265-7279.

[9] J. Zhang, O. Kamdar, W. Le, G.D. Rosen, D. Upadhyay, Nicotine induces resistance to chemotherapy by modulating mitochondrial signaling in lung cancer, Am. J. Respir. Cell Mol. Biol., 40 (2009) 135-146.

[10] M. Xin, X. Deng, Protein phosphatase 2A enhances the proapoptotic function of Bax through dephosphorylation, J. Biol. Chem., 281 (2006) 18859-18867.

[11] M. Xin, X. Deng, Nicotine inactivation of the proapoptotic function of Bax through phosphorylation, J. Biol. Chem., 280 (2005) 10781-10789.

[12] G. Grech, S. Baldacchino, C. Saliba, M.P. Grixti, R. Gauci, V. Petroni, A.G. Fenech, C. Scerri, Deregulation of the protein phosphatase 2A, PP2A in cancer: complexity and therapeutic options, Tumour Biol., 37 (2016) 11691-11700.

[13] D. Haesen, W. Sents, K. Lemaire, Y. Hoorne, V. Janssens, The Basic Biology of PP2A in Hematologic Cells and Malignancies, Front. Oncol., 4 (2014) 347.

[14] I. Cristobal, R. Manso, R. Rincon, C. Carames, C. Senin, A. Borrero, J. Martinez-Useros, M. Rodriguez, S. Zazo, O. Aguilera, J. Madoz-Gurpide, F. Rojo, J. Garcia-Foncillas, PP2A inhibition is a common event in colorectal cancer and its restoration using FTY720 shows promising therapeutic potential, Mol. Cancer Ther., 13 (2014) 938-947. 
[15] J.X. Lin, X.S. Xie, X.F. Weng, C.H. Zheng, J.W. Xie, J.B. Wang, J. Lu, Q.Y. Chen, L.L. Cao, M. Lin, R.H. Tu, C.M. Huang, P. Li, The prognostic value of Cyclin-Dependent Kinase 5 and Protein Phosphatase 2A in Gastric Cancer, J. Cancer, 9 (2018) 4404-4412.

[16] M.P. Ward, J.P. Spiers, Protein phosphatase 2A regulation of markers of extracellular matrix remodelling in hepatocellular carcinoma cells: functional consequences for tumour invasion, Br. J. Pharmacol., 174 (2017) 1116-1130.

[17] M. Janghorban, A.S. Farrell, B.L. Allen-Petersen, C. Pelz, C.J. Daniel, J. Oddo, E.M. Langer, D.J. Christensen, R.C. Sears, Targeting C-MYC by antagonizing PP2A inhibitors in breast cancer, Proc. Natl. Acad. Sci. USA, 111 (2014) 91579162.

[18] I. Cristobal, P. Gonzalez-Alonso, L. Daoud, E. Solano, B. Torrejon, R. Manso, J. Madoz-Gurpide, F. Rojo, J. Garcia-Foncillas, Activation of the Tumor Suppressor PP2A Emerges as a Potential Therapeutic Strategy for Treating Prostate Cancer, Mar. Drugs, 13 (2015) 3276-3286.

[19] J. Li, C. Sheng, W. Li, J.H. Zheng, Protein phosphatase-2A is down-regulated in patients within clear cell renal cell carcinoma, Int. J. Clin. Exp. Pathol., 7 (2014) 1147-1153.

[20] B. Meeusen, V. Janssens, Tumor suppressive protein phosphatases in human cancer: Emerging targets for therapeutic intervention and tumor stratification, Int. J. Biochem. Cell Biol., 96 (2018) 98-134.

[21] H. Liu, Y. Gu, H. Wang, J. Yin, G. Zheng, Z. Zhang, M. Lu, C. Wang, Z. He, Overexpression of PP2A inhibitor SET oncoprotein is associated with tumor progression and poor prognosis in human non-small cell lung cancer, Oncotarget, 6 (2015) 14913-14925. 
[22] N. Lei, B. Peng, J.Y. Zhang, CIP2A regulates cell proliferation via the AKT signaling pathway in human lung cancer, Oncol. Rep., 32 (2014) 1689-1694.

[23] S.A. Saddoughi, S. Gencer, Y.K. Peterson, K.E. Ward, A. Mukhopadhyay, J. Oaks, J. Bielawski, Z.M. Szulc, R.J. Thomas, S.P. Selvam, C.E. Senkal, E. Garrett-Mayer, R.M. De Palma, D. Fedarovich, A. Liu, A.A. Habib, R.V. Stahelin, D. Perrotti, B. Ogretmen, Sphingosine analogue drug FTY720 targets I2PP2A/SET and mediates lung tumour suppression via activation of PP2ARIPK1-dependent necroptosis, EMBO Mol. Med., 5 (2013) 105-121.

[24] Z. Liu, L. Ma, Z.S. Wen, Y.X. Cheng, G.B. Zhou, Ethoxysanguinarine Induces Inhibitory Effects and Downregulates CIP2A in Lung Cancer Cells, ACS Med. Chem. Lett., 5 (2014) 113-118.

[25] P. Neviani, J.G. Harb, J.J. Oaks, R. Santhanam, C.J. Walker, J.J. Ellis, G. Ferenchak, A.M. Dorrance, C.A. Paisie, A.M. Eiring, Y. Ma, H.C. Mao, B. Zhang, M. Wunderlich, P.C. May, C. Sun, S.A. Saddoughi, J. Bielawski, W. Blum, R.B. Klisovic, J.A. Solt, J.C. Byrd, S. Volinia, J. Cortes, C.S. Huettner, S. Koschmieder, T.L. Holyoake, S. Devine, M.A. Caligiuri, C.M. Croce, R. Garzon, B. Ogretmen, R.B. Arlinghaus, C.S. Chen, R. Bittman, P. Hokland, D.C. Roy, D. Milojkovic, J. Apperley, J.M. Goldman, A. Reid, J.C. Mulloy, R. Bhatia, G. Marcucci, D. Perrotti, PP2A-activating drugs selectively eradicate TKI-resistant chronic myeloid leukemic stem cells, J. Clin. Invest., 123 (2013) 4144-4157.

[26] Y. Li, T. Hu, T. Chen, T. Yang, H. Ren, M. Chen, Combination treatment of FTY720 and cisplatin exhibits enhanced antitumour effects on cisplatin-resistant non-small lung cancer cells, Oncol. Rep., 39 (2018) 565-572.

[27] A. Gutierrez, L. Pan, R.W. Groen, F. Baleydier, A. Kentsis, J. Marineau, R. Grebliunaite, E. Kozakewich, C. Reed, F. Pflumio, S. Poglio, B. Uzan, P. 
Clemons, L. VerPlank, F. An, J. Burbank, S. Norton, N. Tolliday, H. Steen, A.P. Weng, H. Yuan, J.E. Bradner, C. Mitsiades, A.T. Look, J.C. Aster, Phenothiazines induce PP2A-mediated apoptosis in T cell acute lymphoblastic leukemia, J. Clin. Invest., 124 (2014) 644-655.

[28] J. Sangodkar, A. Perl, R. Tohme, J. Kiselar, D.B. Kastrinsky, N. Zaware, S. Izadmehr, S. Mazhar, D.D. Wiredja, C.M. O'Connor, D. Hoon, N.S. Dhawan, D. Schlatzer, S. Yao, D. Leonard, A.C. Borczuk, G. Gokulrangan, L. Wang, E. Svenson, C.C. Farrington, E. Yuan, R.A. Avelar, A. Stachnik, B. Smith, V. Gidwani, H.M. Giannini, D. McQuaid, K. McClinch, Z. Wang, A.C. Levine, R.C. Sears, E.Y. Chen, Q. Duan, M. Datt, S. Haider, A. Ma'ayan, A. DiFeo, N. Sharma, M.D. Galsky, D.L. Brautigan, Y.A. Ioannou, W. Xu, M.R. Chance, M. Ohlmeyer, G. Narla, Activation of tumor suppressor protein PP2A inhibits KRAS-driven tumor growth, J. Clin. Invest., 127 (2017) 2081-2090.

[29] R. Tohme, S. Izadmehr, S. Gandhe, G. Tabaro, S. Vallabhaneni, A. Thomas, N. Vasireddi, N.S. Dhawan, A. Ma'ayan, N. Sharma, M.D. Galsky, M. Ohlmeyer, J. Sangodkar, G. Narla, Direct activation of PP2A for the treatment of tyrosine kinase inhibitor-resistant lung adenocarcinoma, JCI Insight, 4 (2019).

[30] L. Tian, X. Zhang, D. Haesen, J. Bravo, J. Fominaya, S. Choquet, J.M. Zini, S. Loisel, E. Waelkens, V. Janssens, A. Rebollo, Identification of PP2A/Set Binding Sites and Design of Interacting Peptides with Potential Clinical Applications, International Journal of Peptide Research and Therapeutics, 24 (2018) 479488.

[31] R.M. De Palma, S.R. Parnham, Y. Li, J.J. Oaks, Y.K. Peterson, Z.M. Szulc, B.M. Roth, Y. Xing, B. Ogretmen, The NMR-based characterization of the FTY720- 
SET complex reveals an alternative mechanism for the attenuation of the inhibitory SET-PP2A interaction, FASEB J, 33 (2019) 7647-7666.

[32] S. Wang, W. Xie, D. Wang, Z. Peng, Y. Zheng, N. Liu, W. Dai, Y. Wang, Z. Wang, Y. Yang, Y. Chen, Discovery of a small molecule targeting SET-PP2A interaction to overcome BCR-ABLT315I mutation of chronic myeloid leukemia, Oncotarget, 6 (2015) 12128-12140.

[33] R. Lajarin-Cuesta, R.L. Arribas, C. Nanclares, E.M. Garcia-Frutos, L. Gandia, C. de Los Rios, Design and synthesis of multipotent 3-aminomethylindoles and 7-azaindoles with enhanced protein phosphatase 2A-activating profile and neuroprotection, Eur. J. Med. Chem., 157 (2018) 294-309.

[34] R. Lajarin-Cuesta, C. Nanclares, J.A. Arranz-Tagarro, L. Gonzalez-Lafuente, R.L. Arribas, M. Araujo de Brito, L. Gandia, C. de Los Rios, Gramine Derivatives Targeting $\mathrm{Ca}(2+)$ Channels and Ser/Thr Phosphatases: A New Dual Strategy for the Treatment of Neurodegenerative Diseases, J. Med. Chem., 59 (2016) 6265-6280.

[35] M. Swingle, L. Ni, R.E. Honkanen, Small-molecule inhibitors of ser/thr protein phosphatases: specificity, use and common forms of abuse, Methods Mol. Biol., 365 (2007) 23-38.

[36] P.K. Kamat, S. Rai, C. Nath, Okadaic acid induced neurotoxicity: an emerging tool to study Alzheimer's disease pathology, Neurotoxicology, 37 (2013) 163172.

[37] A.B. Dounay, C.J. Forsyth, Okadaic acid: the archetypal serine/threonine protein phosphatase inhibitor, Curr. Med. Chem., 9 (2002) 1939-1980. 
[38] Y. Xing, Y. Xu, Y. Chen, P.D. Jeffrey, Y. Chao, Z. Lin, Z. Li, S. Strack, J.B. Stock, Y. Shi, Structure of protein phosphatase $2 \mathrm{~A}$ core enzyme bound to tumorinducing toxins, Cell, 127 (2006) 341-353.

[39] Y. Pang, C. Fang, M.J. Twiner, C.O. Miles, C.J. Forsyth, Total synthesis of dinophysistoxin-2 and 2-epi-dinophysistoxin-2 and their PPase inhibition, Angew. Chem. Int. Ed. Engl., 50 (2011) 7631-7635.

[40] K. Larsen, D. Petersen, A.L. Wilkins, I.A. Samdal, M. Sandvik, T. Rundberget, D. Goldstone, V. Arcus, P. Hovgaard, F. Rise, N. Rehmann, P. Hess, C.O. Miles, Clarification of the C-35 stereochemistries of dinophysistoxin-1 and dinophysistoxin-2 and its consequences for binding to protein phosphatase, Chem. Res. Toxicol., 20 (2007) 868-875.

[41] A. Takai, M. Murata, K. Torigoe, M. Isobe, G. Mieskes, T. Yasumoto, Inhibitory effect of okadaic acid derivatives on protein phosphatases. A study on structureaffinity relationship, Biochem. J., 284 ( Pt 2) (1992) 539-544.

[42] Y. Ichikawa, M. Isobe, T. Goto, Synthesis of a marine polyether toxin, okadaic acid. II. Synthesis of segment B, Tetrahedron, 43 (1987) 4749-4758.

[43] V. Janssens, A. Rebollo, The role and therapeutic potential of Ser/Thr phosphatase PP2A in apoptotic signalling networks in human cancer cells, Curr. Mol. Med., 12 (2012) 268-287.

[44] L. Zhang, H.D. Wang, X.J. Ji, Z.X. Cong, J.H. Zhu, Y. Zhou, FTY720 for cancer therapy (Review), Oncol Rep, 30 (2013) 2571-2578.

[45] M.M. Rahman, L. Prunte, L.F. Lebender, B.S. Patel, I. Gelissen, P.M. Hansbro, J.C. Morris, A.R. Clark, N.M. Verrills, A.J. Ammit, The phosphorylated form of FTY720 activates PP2A, represses inflammation and is devoid of S1P agonism in A549 lung epithelial cells, Sci. Rep., 6 (2016) 37297. 
[46] C. White, H. Alshaker, C. Cooper, M. Winkler, D. Pchejetski, The emerging role of FTY720 (Fingolimod) in cancer treatment, Oncotarget, 7 (2016) 2310623127.

[47] M. Wang, Z.M. Liu, X.C. Li, Y.T. Yao, Z.X. Yin, Activation of ERK1/2 and Akt is associated with cisplatin resistance in human lung cancer cells, J. Chemother., $25(2013)$ 162-169.

[48] T.T. Chao, C.Y. Wang, C.C. Lai, Y.L. Chen, Y.T. Tsai, P.T. Chen, H.I. Lin, Y.C. Huang, C.W. Shiau, C.J. Yu, K.F. Chen, TD-19, an erlotinib derivative, induces epidermal growth factor receptor wild-type nonsmall-cell lung cancer apoptosis through CIP2A-mediated pathway, J. Pharmacol. Exp. Ther., 351 (2014) 352358.

[49] E.J. Kim, H.J. Kim, M.K. Park, G.J. Kang, H.J. Byun, H. Lee, C.H. Lee, Cardamonin Suppresses TGF-beta1-Induced Epithelial Mesenchymal Transition via Restoring Protein Phosphatase 2A Expression, Biomol. Ther. (Seoul), 23 (2015) 141-148.

[50] J. Sangodkar, C.C. Farrington, K. McClinch, M.D. Galsky, D.B. Kastrinsky, G. Narla, All roads lead to PP2A: exploiting the therapeutic potential of this phosphatase, FEBS J, 283 (2016) 1004-1024. 


\section{Declaration of interests}

प The authors declare that they have no known competing financial interests or personal relationships that could have appeared to influence the work reported in this paper.

$\square$ The authors declare the following financial interests/personal relationships which may be considered as potential competing interests: 


\section{Supplementary Information}

\section{An Okadaic Acid Fragment Analogue Prevents Nicotine-Induced Resistance to Cisplatin by Recovering PP2A Activity in Non-Small Cell Lung Cancer Cells}

Raquel L. Arribas ${ }^{a}$, Anna Bordasa, Judit Domènech Omellab, Jose Luis Cedilloa, Veerle Janssens $^{\mathrm{b}}$, Carmen Montiela, ${ }^{\mathrm{a},}$, Cristóbal de los Ríos ${ }^{\mathrm{a}, \mathrm{c}^{*}}$

a Department of Pharmacology and Therapeutic, Universidad Autónoma de Madrid. C/ Arzobispo Morcillo, 4, 28029 Madrid, Spain

${ }^{b}$ Department of Cellular \& Molecular Medicine. Laboratory of Protein Phosphorylation and Proteomics, KU Leuven. Herestraat 49, B-3000 Leuven, \& LKI (Leuven Cancer Institute), Belgium

c Instituto de Investigación Sanitaria, Hospital Universitario de la Princesa. C/ Diego de León, 62, 28006 Madrid, Spain

\section{Contents}

1. Synthesis of ITH12680 S2

2. NMR spectra of ITH12680 S4

3. Molecular docking of ITH12680 with PP2A S5

4. Cell cultures and reagents $\quad$ S5

5. Cell transfection and immunoprecipitation $\quad$ S6

$\begin{array}{ll}\text { 6. PP2A activity assays } & \text { S7 }\end{array}$

$\begin{array}{ll}\text { 7. Cell viability by the MTT reduction assay } & S 7\end{array}$

8. Determination of apoptosis by flow cytometry S8

9. Western-blot analyses $\quad$ S9

$\begin{array}{ll}\text { 10. Statistical analysis } & \text { S9 }\end{array}$

$\begin{array}{ll}\text { 11. References } & \mathrm{S} 10\end{array}$

E-mail: cristobal.delosrios@inv.uam.es,carmen.montiel@uam.es 


\section{Synthesis of ITH12680}

\subsection{Materials and Methods}

D-glucal triacetate, allyltrimethylsilane, boron trifluoride diethyletherate, were purchased from Sigma/Merck (Madrid, Spain). Sodium sulfate was purchased from LabKhem (Mataró, Spain), and solvents used for synthesis, isolation, with analytical grade, were purchased from VWR (Barcelona, Spain). Reaction was monitored with TLC at $254 \mathrm{~nm}$ UV light, using silica gel (60 Å) as stationary phase purchased from Sigma/Merck. Reaction was carried out in glassware systems purged from air with vacuum/argon cycles and run under Ar atmosphere. Melting point was obtained with a Stuart SMP-10 apparatus (Staffordshire, UK), without correction. MS spectra were acquired in an ABSciex QSTAR spectrometer under the high-resolution configuration with electrospray as ionization source. ${ }^{1} \mathrm{H}$ and ${ }^{13} \mathrm{C}$ NMR spectra were acquired in a Bruker AVANCE $300 \mathrm{MHz}$ station (corresponding to a $75.4 \mathrm{MHz}$ for the ${ }^{13} \mathrm{C}$ detection), expressed as ppm, and calibrated upon the residual ${ }^{1} \mathrm{H}$ signal from deuterated chloroform for ${ }^{1} \mathrm{H}-\mathrm{NMR}$, or its corresponding ${ }^{13} \mathrm{C}$ signals for ${ }^{13} \mathrm{C}-\mathrm{NMR}$. Purity of the compound was confirmed by elemental analysis in a LECO CHNS-932 station.

\subsection{Experimental procedure}

ITH12680 was synthetized following a protocol previously described [1]. D-glucal triacetate $6.10 \mathrm{~g}, 22.43 \mathrm{mmol})$ was dissolved in dichloromethane $(23 \mathrm{~mL})$ at $-50{ }^{\circ} \mathrm{C}$ under argon. Allyltrimethylsilane (3.56 mL, $2.56 \mathrm{~g}, 22.43 \mathrm{mmol})$ and $\mathrm{BF}_{3}-\mathrm{Et}_{2} \mathrm{O}(2.84 \mathrm{~mL}, 3.18 \mathrm{~g}, 22.43 \mathrm{mmol})$ were slowly added and the mixture maintained at $-50^{\circ} \mathrm{C}$ for $1.5 \mathrm{~h}$. After this time, reaction was allowed to warm up to $0^{\circ} \mathrm{C}$ and a saturated aqueous solution of $\mathrm{NaHCO}_{3}(20 \mathrm{~mL})$ was added up to get $\mathrm{pH} 7$. The mixture was extracted with dichloromethane $(3 \times 20 \mathrm{~mL})$. The 
combined organic layer was dried over anhydrous $\mathrm{Na}_{2} \mathrm{SO}_{4}$, filtered, and evaporated under vacuum. The compound ITH12680, [(2R,3S,6R)-3-acetoxy-6-alyl-3,6-dihidro-2H-pyran-2yl]methyl acetate, was obtained with quantitative yield, showing spectral and analytical data according to its structure. $[\alpha]^{25}{ }_{\mathrm{D}}+78.9\left(\mathrm{c} 1.4, \mathrm{CH}_{2} \mathrm{Cl}_{2}\right)$.

${ }^{1} \mathrm{H}$ NMR $\left(\mathrm{CDCl}_{3}, 300 \mathrm{MHz}\right) \delta 5.66(\mathrm{dd}, \mathrm{J}=1.2 \mathrm{~Hz}, 10.5 \mathrm{~Hz}, 1 \mathrm{H}, \mathrm{H} 3), 5.61-5.46(\mathrm{~m}, 2 \mathrm{H}, \mathrm{H} 4$, $\mathrm{H} 8)$, 4.88-4.75 (m, 3H, H2, H9), 4.03-3.77 (m, 3H, H1, H10), 3.65 (m, 1H, H5), 2.22-1.94 (2m, 2H, H7), $1.78\left(\mathrm{~s}, 3 \mathrm{H}, \mathrm{CH}_{3}\right), 1.75\left(\mathrm{~s}, 3 \mathrm{H}, \mathrm{CH}_{3}\right)$.

${ }^{13} \mathrm{C} \mathrm{NMR}\left(\mathrm{CDCl}_{3}, 300 \mathrm{MHz}\right) \delta 169.5,169.3,133.7,132.2,123.2,116.6,70.5,69.1,64.3,62.1$, $37.1,20.1,19.9$

HRMS (API-ES+) m/z calcd. for $\mathrm{C}_{13} \mathrm{H}_{18} \mathrm{O}_{5} \mathrm{Na} 277.1052\left(\mathrm{M}+\mathrm{Na}^{+}\right)$; found 277.1058 ( $\left.\pm 2.2 \mathrm{ppm}\right)$.

Elem. Anal. calcd. for $\mathrm{C}_{13} \mathrm{H}_{18} \mathrm{O}_{5} \cdot 1 / 2 \mathrm{H}_{2} \mathrm{O}: \mathrm{C}, 59.30 ; \mathrm{H}, 7.27$; found: $\mathrm{C}, 59.43 ; \mathrm{H}, 6.78$. 
2. NMR spectra of ITH12680
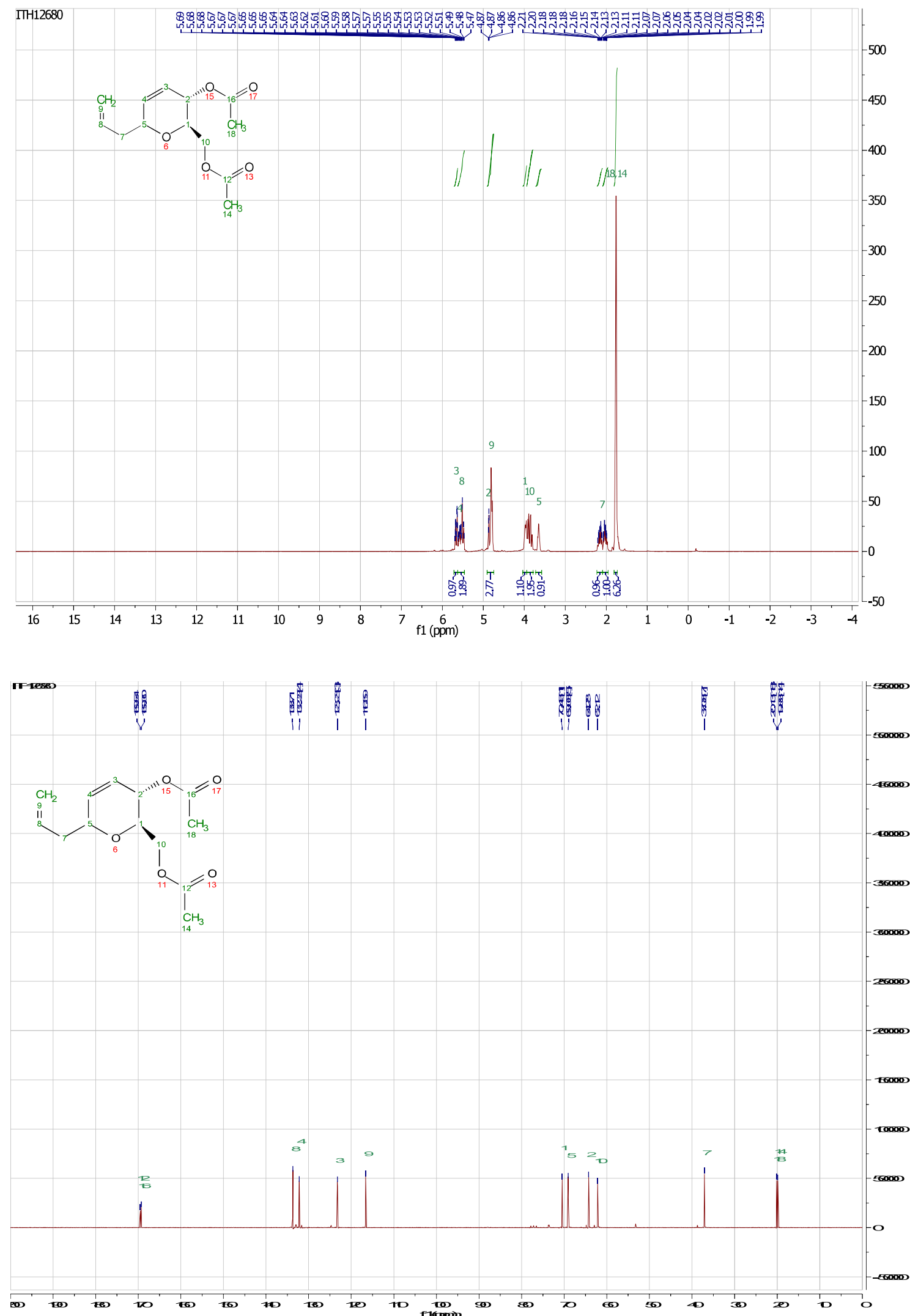


\section{Molecular docking of ITH112680 with PP2A}

The conformation of ITH12680 was obtained using the Spartan version 14 (Wavefunction, Inc.; Irvine, CA) by Monte Carlo, optimizing the most stable conformation under a HF methodbased ab initio base $6-31 G^{*}$. To run the docking experiments, the $3 D$ structure of the PP2A AC core enzyme deposited in the protein data bank (www.rcsb.org; PDB ID: 2IE4, removing the co-crystalized inhibitor $O A$ and the water molecules) was selected[2], and the calculations carried out in the Molegro Virtual Docker v. 3.2.1 software. The algorithm used for ranking the best energies was MolDock Score.[3]

\section{Cell cultures and reagents}

Human NSCLC cell line A549 and HEK293T cells were purchased from American Type Culture Collection (ATCC), and respectively maintained in RPMI 1640 (Gibco, Thermo Fischer Scientific, Waltham, MA, USA) and HEK media, both supplemented with $10 \%$ fetal bovine serum (FBS). Cells were cultured in an incubator at $37{ }^{\circ} \mathrm{C}$ under a moisture-saturated air atmosphere with $5 \% \mathrm{CO}_{2}$.

Nicotine, cisplatin, and FTY720 were purchased from Sigma/Merck (Madrid, Spain). Okadaic acid sodium salt was obtained from Calbiochem, and the colorimetric dye MTT was purchased from Sigma/Merck. The Annexin V- FITC kit used was purchased from Immunostep (Salamanca, Spain).

We used the following primary antibodies: rabbit anti-Bax (Cell Signaling Technology); rabbit anti-AKT and rabbit anti-p-AKT (Cell Signaling Technology); mouse anti-ERK1/2 and mouse anti-p-ERK1/2 (Santa Cruz Biotechnologies), rabbit anti-CIP2A, goat anti-SET (kindly provided 
by I. Cristóbal, IIS-Fundación Jimenez Díaz, Madrid, Spain), goat anti- $\beta$-actin (Santa Cruz Biotechnologies, CA,USA)], mouse anti-GFP (generously supplied by Dr. P. Parker at the Francis Crick Institute, London, UK), mouse anti-PP2A-A subunit and mouse anti-PP2A-C subunit (generously supplied by Dr. S. Dilworth, Middlesex University, London, UK). The PP2A B-type subunit coding regions for human B55a and human B56a were cloned in the pEGFP. TEV vector using In-Fusion HD technology (Clontech Laboratories). The PP2A Ca coding region was cloned in the pEGFP-C1 vector (Clontech).

\section{Cell transfection and immunoprecipitation}

HEK293T cells were transfected with the appropriate PP2A subunit expression vectors using PEI transfection reagent according to a standard protocol. Forty-eight hours post-transfection, lysates were rinsed with TBS and lysed with $200 \mu \mathrm{L}$ NET buffer $(50 \mathrm{mM}$ Tris- $\mathrm{HCl}$ pH 7.4, 150 $\mathrm{mM} \mathrm{NaCl}, 15 \mathrm{mM}$ EDTA, 1\% NP-40) supplemented with a complete protease inhibitor cocktail (Roche Applied Science), and centrifuged for $15 \mathrm{~min}$ at 13,000 $\mathrm{g}$.

For pull-down experiments, cell lysates were incubated with $30 \mu \mathrm{L}$ GFP-trapping beads (ChromoTek) and $500 \mu \mathrm{L}$ NENT100 buffer (20 mM Tris-HCl pH 7.4, 1 mM EDTA, 0.1\% NP-40, $25 \%$ glycerol, $100 \mathrm{mM} \mathrm{NaCl}$ ), supplemented with $1 \mathrm{mg} / \mathrm{mL}$ bovine serum albumin (BSA) on a rotating wheel for $1 \mathrm{~h}$, at $4^{\circ} \mathrm{C}$. Then, the beads were washed twice in NENT100 containing $\mathrm{BSA}$, and twice in NENT300 containing $300 \mathrm{mM} \mathrm{NaCl}$. Bound proteins were eluted in 2x Nupage sample buffer (Invitrogen) and boiled at $98{ }^{\circ} \mathrm{C}$ for $10 \mathrm{~min}$. The eluted proteins were analyzed by SDS-PAGE on $4 \%-12 \%(w / v)$ Bis-Tris gels (BioRad) and immunoblotted. The membranes were blocked in 5\% milk in TBS and $0.1 \%$ Tween-20 for $1 \mathrm{~h}$ at room temperature and incubated with primary antibodies overnight at $4{ }^{\circ} \mathrm{C}$. After being washed in TBS and $0.1 \%$ 
Tween-20, the membranes were incubated at RT for $1 \mathrm{~h}$ with horseradish-peroxidaseconjugated secondary antibodies (Dako) and developed on an ImageQuant LAS 4000 system (GE Healthcare) with a WesternBright ECL detection kit (Advansta). Densitometric quantification was done with ImageJ. For statistics, we applied one-way multiple comparison ANOVA to the average values of all the quantified bands for a given condition on a given gel.

\section{PP2A activity assays}

After GFP pull-down, PP2A-GFP-trapped complexes were washed with $500 \mu \mathrm{L} 20 \mathrm{mM}$ Tris$\mathrm{HCl}(\mathrm{pH}$ 7.4) and $1 \mathrm{mM}$ DTT (TrisDTT) and resuspended in $100 \mu \mathrm{L}$ TrisDTT solution. $20 \mu \mathrm{L}$ of PP2A-GFP complex diluted as necessary were pre-incubated (10 min on ice) with OA (Calbiochem) and with or without ITH12680 for 10 min on ice, before addition of $10 \mu \mathrm{L}$ of $2 \mathrm{mM}$ stock of K-R-pT-I-R-R phospho-peptide for $15-30$ min at $30{ }^{\circ} \mathrm{C}$ (still in the linear range of the assay). The released free phosphate was determined by the addition of BIOMOL Green (catalog no. BMLAK111-0250, Enzo). After $10 \mathrm{~min}$ of incubation at room temperature, absorbance at $630 \mathrm{~nm}$ was measured in a multi-channel spectrophotometer. We subsequently obtained specific phosphatase activity by correcting the measured absorbance for the amount of $C$ subunit pulled by the GFP-tagged $B$ subunit, as determined by immunoblotting with anti-C antibodies and signal quantification by ImageJ.

\section{Cell viability by the MTT reduction assay}

Cell viability was assessed by the quantitative colorimetric method of the MTT reduction. Briefly, only in living cells, the yellow-colored MTT (3-[4,5-dimethylthiazol-2-yl]-2,5- 
diphenyltetrazolium bromide is chemically reduced by mitochondrial dehydrogenase enzymes. This indirectly measures cell viability as the mitochondrial activity in healthy cells. The reduced MTT is a purple-colored formazan derivative that is dissolved in DMSO and offers a concentration-dependent colorimetric signal at $540 \mathrm{~nm}$. A549 cells were seeded in 96-well plates $\left(2 \times 10^{3}\right.$ cells/plate), and $100 \mu \mathrm{L}$ of medium volume. Twenty-four hours later, plates were pre-treated with the compound ITH12680 or FTY720. After 48 h co-treatment, MTT dissolved in water at $10 \mathrm{mg} / \mathrm{mL}$ was added to the wells (final concentration of $0.3 \mathrm{mg} / \mathrm{mL}$ ), and incubated in the dark at $37^{\circ} \mathrm{C}$ for $3 \mathrm{~h}$. After harvesting the medium, cells and tissue were lysed and the formazan dissolved with DMSO. Absorbance was measured at $540 \mathrm{~nm}$ in a colorimetric plate reader (FLUOstar Optima, BMG, Germany). Data were expressed as cell viability percentage, taking the obtained absorbance value in untreated cells as $100 \%$.

\section{Determination of apoptosis by flow cytometry}

Cells were seeded in $60 \mathrm{~mm}$ plates $\left(12 \times 10^{4}\right.$ cells/plate), and $2 \mathrm{~mL}$ of medium volume. Twenty-four hours later, plates were pre-treated with the compound ITH12680 and/or nicotine. Twenty-four hours after that, cells were co-incubated with cisplatin with or without nicotine and/or ITH12680. After $48 \mathrm{~h}$ co-treatment, the individual cells were collected and resuspended with PBS. After trypsinization, cells were washed with PBS three times. After treatment, cells were stained with Annexin V-FITC and IP using the Annexin V-FITC Apoptosis Detection Kit (Immunostep) following the manufacturer's instructions. The apoptosis rate was analyzed by flow cytometry (FC500 MPL Flow Cytometer, SIDI-UAM). Each condition was tested in duplicate and three experiments were done. 


\section{Western-blot analyses}

After being subjected to the indicated treatments, cells were lysed and protein concentration determined in the cell lysates, as described elsewhere. Proteins were resolved by $10 \%$ SDS/PAGE gel electrophoresis, transferred to a PVDF membrane (Millipore) and analyzed by immunoblot after overnight incubation of the blots at $4{ }^{\circ} \mathrm{C}$ with the following primary antibodies (anti- $\beta$-catenin, anti-vimentin or anti-fibronectin), at 1:100 dilution. The anti- $\beta$-actin antibody $(1: 1000)$ was incubated for $1 \mathrm{~h}$, at rt. Proteins were detected by blot incubation $(1 \mathrm{~h})$ with the appropriate HRP conjugated secondary antibody (1:5000, Santa Cruz Biotechnologies, CA, USA). The resulting bands were detected using the ECL Select Western Blotting Detection Reagent (Amersham, GE Healthcare, UK).

\section{Statistical Analysis}

Sample sizes $(n)$ for the experiments were calculated according to the formula $n=Z^{2} \cdot s^{2} / e^{2}$, taking a confidence interval $(Z)$ of $95 \%$, error margin $(e)$ of $5 \%$, and a averaged standard deviation (s) of 0.05 , obtaining a sample size of 3 . The Mann-Whitney test was used for comparisons between two groups, and one-way ANOVA followed by Dunnett's post-hoc test for multiple comparisons. GraphPad Prism 7.0 software was used for the statistical

calculations. Data were reported as mean \pm standard error of the mean (SEM). A $p$ value $\leq$ 0.05 was considered statistically significant. 


\section{References}

[1] Y. Ichikawa, M. Isobe, T. Goto, Synthesis of a marine polyether toxin, okadaic acid. II. Synthesis of segment B, Tetrahedron, 43 (1987) 4749-4758.

[2] Y. Xing, Y. Xu, Y. Chen, P.D. Jeffrey, Y. Chao, Z. Lin, Z. Li, S. Strack, J.B. Stock, Y. Shi, Structure of protein phosphatase 2A core enzyme bound to tumor-inducing toxins, Cell, 127 (2006) 341-353.

[3] R. Thomsen, M.H. Christensen, MolDock: a new technique for high-accuracy molecular docking, J. Med. Chem., 49 (2006) 3315-3321. 